Reprod. Nutr. Dévelop., 1988, 28 Suppl. n 1, 157-158

\title{
Anticorps contre les protéines alimentaires et perméabilité intestinale aux macromolécules chez le veau préruminant recevant de la farine de pois
}

I. NUNES DO PRADO, R. TOULLEC, J. P. LALLES, L. HINGAND ( $\left.{ }^{1}\right)$, J. GUÉGUEN $\left({ }^{2}\right)$

Laboratoire du Jeune Ruminant.

(1) Laboratoire de Pathologie Végétale,

I.N.R.A., 65, rue de Saint-Brieuc, 35042 Rennes Cedex, France.

$\left({ }^{2}\right)$ Laboratoire de Biochimie et Technologie des Protéines,

I.N.R.A., rue de la Géraudière, 44072 Nantes Cedex.

Summary. Feeding a milk-substitute diet containing raw pea flour to preruminant calves resulted in the production of anti-pea protein antibodies. Immunoreactive legumin could be evidenced in blood plasma between the second and the fifth meal. Plasma immunoreactive $\beta$-lactoglobulin increased up to the third or seventh week and decreased thereafter, showing a transient rise of gut permeability to macromolecules probably due to intestinal inflammatory reactions.

L'ingestion de soja par le veau préruminant peut provoquer la formation d'anticorps dirigés contre les protéines alimentaires et des altérations de la paroi intestinale, entraînant notamment une augmentation de la perméabilité aux macromolécules (Kilshaw et Sissons, 1979 ; Kilshaw et Slade, 1980). Le but de ce travail a été d'étudier l'effet des protéines de pois.

Matériel et méthodes. Cinq veaux préruminants de $39 \pm 10 \mathrm{j}$ en début d'essai, ont reçu 43 repas d'épreuve d'un lait de remplacement dans lequel les protéines étaient apportées par une farine de pois cru et de la poudre de lait écrémé ( 38 et $62 \%$ ). Ces repas ont eu lieu le matin, 3 fois par semaine pendant les 4 premières semaines ( $P 1)$, puis tous les jours pendant les 4 suivantes ( $P 2)$. Des prises de sang ont été effectuées $4 \mathrm{~h}$ après le repas lors de chaque jour d'épreuve (P1) ou au milieu de chaque semaine (P2). Les titres d'anticorps dirigés contre les protéines totales du pois et les deux principales d'entre elles (légumine et viciline) ont été déterminés dans le plasma par hémagglutination passive (Kilshaw et Sissons, 1979) et par ELISA (Kilshaw et Slade, 1980). La légumine et la $\beta$-lactoglobuline ( $\beta \mid \mathrm{b}$ ) immunoréactives ont été dosées par ELISA.

Résultats et discussion. En hémagglutination passive, les titres d'anticorps dirigés contre les protéines totales et la viciline, initialement nuls, se sont élevés régulièrement après le $6^{\mathrm{e}}$ repas (fig. $1 \mathrm{~A}$ ); en revanche, le titre anti-légumine $\mathrm{n}^{\prime} \mathrm{a}$ pas augmenté au-delà du $9^{e}$ repas. En ELISA, les faibles titres trouvés au départ pourraient être dus en partie à une absorption non spécifique des anticorps dans les faibles dilutions sériques (fig. 1B); leur accroissement s'est infléchi au-delà du $15^{\mathrm{e}}$ repas et a duré aussi longtemps à l'égard de la légumine que contre les protéines totales et la viciline. De la légumine immunoréactive a été détectée dans 

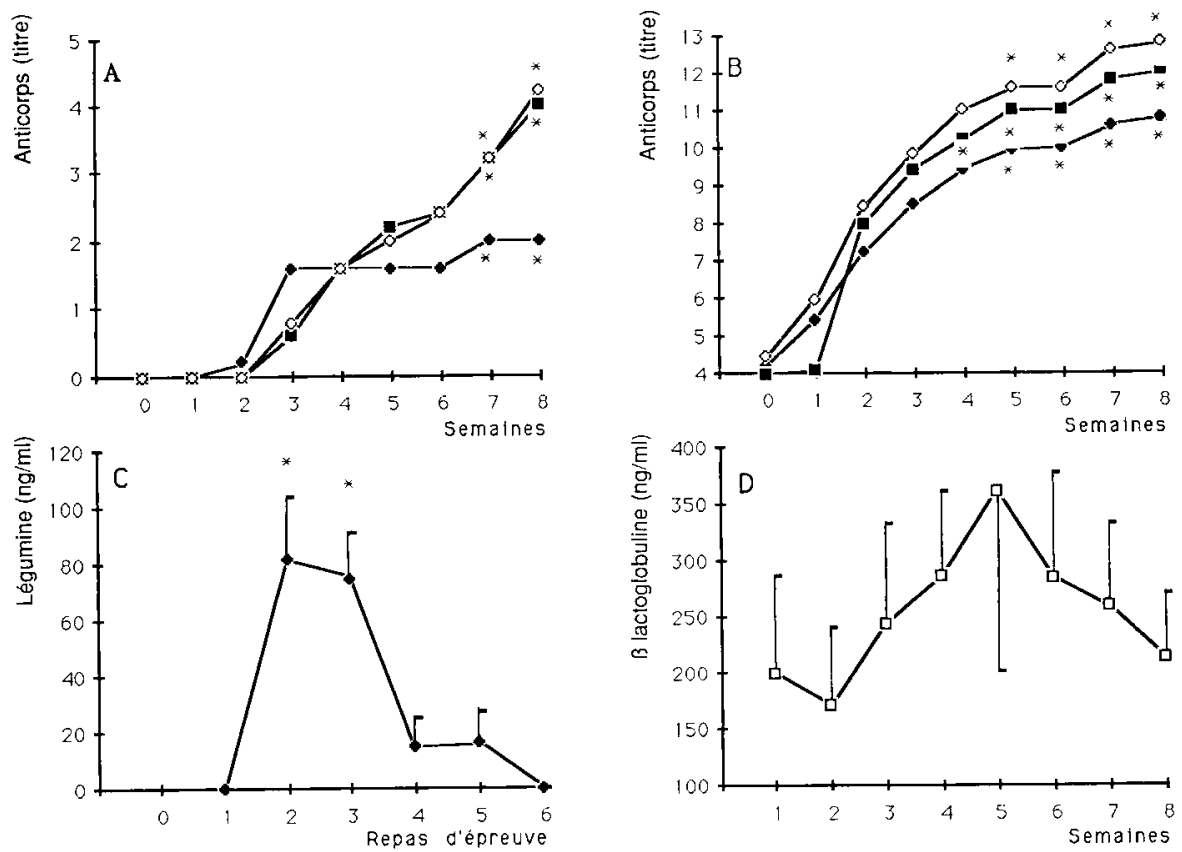

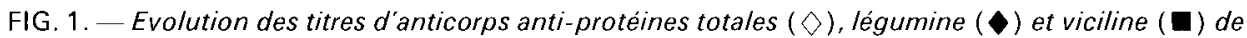
pois déterminés par hémagglutination passive (A) ou par ELISA (B), et des taux de légumine (C) et de $\beta$-lactoglobuline (D) immunoréactives, dans le plasma des veaux (titres: nombre maximum de dilutions au demi permettant d'obtenir l'agglutination d'érythrocytes garnis d'antigènes ou une densité optique de 0,2 à partir d'une dilution initiale au vingtième). ( ${ }^{*}$ : valeur significativement différente du minimum, au seuil 0,05 , d'après le test de Friedman.)

le plasma, mais seulement du $2^{\mathrm{e}}$ au $5^{\mathrm{e}}$ repas (fig. $1 \mathrm{C}$ ). La quantité d'anticorps synthétisés semble donc avoir été rapidement suffisante pour empêcher son absorption ou, plus vraisemblablement, pour saturer tous ses épitopes. Le taux plasmatique de $\beta \mathrm{lg}$ immunoréactive (fig. 1D) a augmenté jusqu'à une valeur maximum, atteinte, suivant le veau, entre le $9^{\mathrm{e}}$ et le $36^{\mathrm{e}}$ repas d'épreuve (augmentation moyenne de $318 \%$ entre le minimum et le maximum ; $P<0,02$ ), puis a baissé. La $\beta \mathrm{lg}$ n'étant pas considérée comme provoquant la formation d'anticorps chez le veau (Kilshaw et Slade, 1980), ces résultats indiquent que le pois a entraîné une augmentation de la perméabilité intestinale aux macromolécules qui s'est atténuée avec le temps.

En conclusion, chez le veau préruminant, les protéines de pois franchissent partiellement la barrière intestinale et provoquent des réactions immunitaires. On observe parallèlement une augmentation de l'absorption des macromolécules, probablement due à une altération de la muqueuse intestinale. 